\title{
MEDIAÇÃO PEDAGÓGICA TUTORIAL NA EDUCAÇÃO A DISTÂNCIA: UM ESTUDO DA PERCEPÇÃO DOS TUTORES
}

\author{
MACAPÁ/AP JUNHO/2018 \\ Eniel do Espírito Santo - UFRB - enielsanto@gmail.com \\ Elisângela Lima de Andrade - UNIFAP - elisangelaandradebogea@gmail.com \\ Tipo: Investigação Científica (IC) \\ Natureza: Relatório Final de Pesquisa \\ Categoria: Conteúdos e Habilidades \\ Setor Educacional: EDUCAÇÃO SUPERIOR
}

\begin{abstract}
RESUMO
A Educação a Distância é uma modalidade que se caracteriza, entre outras coisas, pela prática tutorial, tendo os tutores virtual e presencial como peças fundamentais no processo de ensino e aprendizagem. Como parte da equipe polidocente, os tutores são responsáveis pela mediação pedagógica com os estudantes geograficamente espalhados. Este estudo tem por objetivo analisar as percepções de um grupo de tutores quanto à mediação pedagógica implementada no ciberespaço educativo. Do ponto de vista metodológico, caracteriza-se como uma pesquisa exploratória e descritiva, com abordagem qualitativa que utilizou como procedimento de coleta de dados um levantamento com 25 tutores da educação a distância, vinculados à Universidade Federal do Amapá. Do estudo emergiram categorias de análise que apontaram para a percepção positiva da interação com o estudante; avaliam a formação inicial e continuada como adequadas e compreendem que a produção do material didático não deve fazer parte da atribuição tutorial. O estudo conclui apontando a relevância da formação para que a equipe tutorial seja capaz de desenvolver um processo de mediação pedagógica compatível com a demanda da educação a distância.
\end{abstract}

Palavras-chave: Educação a distância. Tutor de EaD. Mediação pedagógica. Equipe polidocente.

\section{AGRADECIMENTOS}




\section{Introdução}

Em pleno século XXI, numa sociedade da informação, interconectada e mediada pela tecnologia, é possível dizer que a Educação a Distância é uma modalidade consolidada no Brasil e no mundo. De acordo com o Censo EAD.BR 2016 (ABED, 2017), o país tinha, em 2016, 561.667 estudantes matriculados em cursos regulamentados totalmente a distância; 217.175, em cursos regulamentados semipresenciais; e 2.956.045, em cursos livres corporativos e não corporativos.

O crescimento da EaD no país deve continuar, pois o Decreto 9.057, de 25 de maio de 2017, trouxe mudanças em relação ao credenciamento de instituições educacionais para a oferta da modalidade no ensino superior e na pós-graduação. A partir de agora, os estabelecimentos privados não precisam mais oferecer ensino presencial para pedir credenciamento para a EaD, ou seja, podem ter, exclusivamente cursos e programas a distância. Além disso, não há mais exigência de que as instituições públicas de ensino superior se credenciem para oferecer a modalidade:

\footnotetext{
Art. 12. As instituições de ensino superior públicas dos sistemas federal, estaduais e distrital ainda não credenciadas para a oferta de cursos superiores na modalidade a distância ficam automaticamente credenciadas, pelo prazo de cinco anos, contado do início da oferta do primeiro curso de graduação nesta modalidade, condicionado à previsão no Plano de Desenvolvimento Institucional (BRASIL, 2017, s.p.).
}

As novas regras demonstram a intenção do governo brasileiro de facilitar o processo de credenciamento das instituições de ensino, públicas e privadas, à EaD. O que torna ainda mais relevante esta pesquisa, na medida em que fortalece a modalidade e o consequente aumento de programas, cursos, ferramentas, discentes e docentes na Educação a Distância.

Para Aretio (2017), mesmo com as resistências, ainda, existentes em relação ao ensino a distância, a EaD vem provando que pode ser tão bem-sucedida quanto a educação presencial. O autor espanhol, que é um dos maiores estudiosos do tema na atualidade, defende que a qualidade dos desenhos pedagógicos dos cursos a distância, a flexibilidade, a inovação e a possibilidade de aprendizagem permanente estão entre os fatores da expansão e da consolidação da modalidade.

As formas de ensinar a distância mudaram ao longo do tempo devido à introdução das tecnologias digitais de informação e comunicação (TDIC), no entanto, a figura do tutor continua sendo considerada de grande importância no processo de ensino e aprendizagem. Chacón e Herrera (2016) constataram isso numa investigação recente, realizada numa universidade industrial da Colômbia: 
La figura de "orientador" se señaló como efectiva y con aportes notorios. El acompañamiento del orientador fue pieza clave para los estudiantes que ingresaron al programa, especialmente para los tardíos. El proceso de adaptación del estudiante a la modalidad virtual tiene que darse con un acompañamiento en asistencia tecnológica y académica (CHACÓN; HERRERA, 2016, p. 11).

De acordo com Mill (2012), o tutor faz parte da equipe polidocente da Educação a Distância. Normalmente, ele migra da sala de aula convencional para a EaD, muitas vezes sem ter preparação adequada para atuar nessa modalidade. É um docente que aprende a ser tutor com a prática, o que pode gerar frustração para ele e para os estudantes. Um dilema observado por Chaquime e Mill (2016) no Brasil e por Moore e Kearsley (2010) nos Estados Unidos.

Indubitavelmente, não são poucos os desafios de um tutor de EaD. Para Pagano (2007), os obstáculos têm a ver com as características da própria modalidade, como: a distância geográfica entre aluno e professor; a utilização de tecnologia; o trabalho baseado no apoio tutorial; a aprendizagem mais flexível; e a comunicação massiva e bidirecional. Sendo que esta última pode se transformar em comunicação multidirecional quando o curso possibilita a interação entre os estudantes, o que vem se tornando uma tendência dentro do contexto da aprendizagem colaborativa.

O objetivo principal deste artigo, portanto, é demonstrar a percepção dos tutores da instituição pesquisada em relação à prática pedagógica, incluindo o papel da mediação pedagógica, da interação entre tutor e estudantes e da formação inicial e continuada desse mediador da EaD.

Diante desse cenário, este artigo é um recorte de uma pesquisa mais ampla, que analisou a prática tutorial de um programa de $\mathrm{EaD}$ de uma instituição de ensino superior pública do norte do país, vinculada à Universidade Aberta do Brasil (UAB). Apresenta-se a análise dos resultados de um questionário aplicado a 25 tutores da instituição pesquisada, que era o universo de tutores do programa na ocasião da investigação, realizada em meados de 2017.

\section{Referencial Teórico}

Os cursos de graduação e pós-graduação, devidamente regulamentados por lei, são semipresenciais, com a maior parte do curso sendo ministrada virtualmente, e alguns encontros presenciais. Portanto, normalmente, os cursos têm tutores virtuais e presenciais, que, no caso da instituição pesquisada, ministra as aulas nos encontros presenciais. 
Antes da instituição do primeiro sistema de educação obrigatória, no século XVII, na antiga Prússia, apenas os ricos tinham acesso à aprendizagem formal (ROTHBARD, 2013). O ensino acontecia de maneira individual, na casa do aprendiz, e o professor era um tutor. Segundo Aretio (1999, p. 02), "La palabra tutor lleva implícita la figura por la que se ejerce la protección, la tutela, defensa o salvaguardia de una persona menor o necesitada, en su primera acepción [...]".

$\mathrm{Na}$ Educação a Distância, ainda de acordo com o autor espanhol, o tutor é um orientador no processo de ensino e aprendizagem do estudante "solitário" e distante geograficamente. O pensamento de Aretio (1999) se coaduna com o de Vygotsky (1896-1934) ao creditar ao tutor a tarefa de interação, ou seja, o tutor é o mediador, que deve usar estratégias adequadas para manter o aluno a distância "dentro" do curso.

Portanto, a mediação pedagógica e a interação com os estudantes são funções fundamentais dos tutores de EaD. Para que elas sejam exercidas de forma satisfatória, promovendo a construção do conhecimento, as formações inicial e continuada são de suma importância para a prática tutorial.

Para trabalhar como tutor na $\mathrm{EaD}$, no âmbito da $\mathrm{UAB}$, a Portaria 183 diz que o mesmo deve ter nível superior e, pelo menos, um ano de experiência no magistério no ensino básico ou superior (BRASIL, 2016). Já a Resolução n. 1, também de 2016, diz que o tutor deve atuar na área de conhecimento de sua formação. Ou seja, uma pessoa graduada em matemática não deveria trabalhar na tutoria de um curso EaD na área de Letras, por exemplo.

Podemos afirmar, portanto, que o tutor não precisa ter formação inicial em pedagogia ou ter cursado algum tipo de licenciatura para exercer essa atividade. Voltando-se para a educação presencial, no ensino superior, há uma discussão em relação à formação inicial dos professores. Para lecionar numa faculdade e/ou universidade, não se exige licenciatura e/ou pedagogia. Algo considerado polêmico, pois, teoricamente, o professor não estudou para ser professor.

\footnotetext{
[...] A grande maioria dos docentes são bacharéis e, em geral, nunca frequentaram uma formação pedagógica para atuar como professores na universidade e nas faculdades. Alguns docentes que atuam na educação superior optam por mestrados e doutorados em educação, ou seja, o nível stricto sensu, para buscar tal formação, mas, embora necessária, não tem sido suficiente para propor uma pedagogia universitária adequada às exigências atuais da Sociedade e da Educação [...] (DOS SANTOS JUNGES; BEHRENS, 2015, p. 286).
}

Para as autoras, essa formação stricto sensu acaba levando o docente a se dedicar mais à pesquisa do que ao ensino, o que pode ser prejudicial à prática docente. 
Segundo elas, uma forma de os professores amenizarem a ausência de uma formação pedagógica inicial é a formação continuada, que pode ser desenvolvida na própria instituição de ensino em que trabalham (DOS SANTOS JUNGES; BEHRENS, 2015).

As pesquisadoras ressaltam que cursos de capacitação, normalmente de curta duração, não são suficientes e que é necessária uma formação continuada que promova a reflexão do professor sobre sua prática pedagógica. Recursos didáticos diferenciados, avaliações que atendam às necessidades dos alunos, além da consciência da necessidade de uma aprendizagem mais significativa são elementos fundamentais num processo de formação pedagógica continuada. E acrescentam:

\footnotetext{
Nesse sentido, a docência universitária numa perspectiva inovadora, que entende o professor como agente social, o aluno como cidadão crítico e a instituição educativa como campo de produção do conhecimento, exige um comprometimento com a aprendizagem, ao longo de toda a vida, num movimento dinâmico de mudança, de açãoreflexão-ação e de articulação da teoria e da prática (DOS SANTOS JUNGES; BEHRENS, 2015, p. 310).
}

Então, na EaD, encontramos alguns dilemas em relação à formação docente: falta de formação inicial em pedagogia, carência de formação continuada e ausência de experiência na própria Educação a Distância. Afinal, como já foi demonstrado aqui, tanto no Brasil (MILL, 2012) quanto nos Estados Unidos (MOORE; KEARSLEY, 2010), os tutores aprendem fazendo.

\section{Procedimentos metodológicos}

Este estudo se configura como uma pesquisa exploratória e descritiva, com abordagem qualitativa que contou como procedimento de coleta de dados um levantamento com 25 tutores vinculados à educação a distância na UNIFAP, em 2017. O instrumento da pesquisa foi um questionário eletrônico composto por 24 itens, tendo sido respondido por 24 tutores que compõe a amostra aleatória simples.

O projeto de pesquisa foi previamente submetido para a apreciação ética pelo Conselho Nacional de Ética em Pesquisa (CONEP), tendo sido aprovado pelo Comitê de Ética em Pesquisa (CEP) da SEAMA, sob o número 2.089.731.

\section{Análise e discussão}

A partir das respostas dos tutores, via questionário, foi possível construir algumas categorias de análises, apresentadas a seguir. 
Nesta categoria, foi possível identificar que os tutores da EaD da Unifap consideram a interação tutor-estudante adequada e positiva. Isso fica evidenciado nas respostas sobre o acesso à plataforma Moodle, que acontece diariamente; o retorno às solicitações dos estudantes, que os tutores disseram dar em, no máximo, 48 horas. Uma agilidade necessária na Educação a Distância, corroborada por pesquisas recentes, como a de Chacón e Herrera (2016), que afirmam a importância do tutor no processo de ensino e aprendizagem na EaD.

Mesmo num mundo digitalizado e numa modalidade em que o estudante precisa ser mais autônomo e independente (MOORE, 2002), a figura do tutor ainda permanece indispensável na $\mathrm{EaD}$, sendo que esse tutor precisa ser ágil, presente e incentivador do aprendente (FAHARA; CASTRO, 2015). De acordo com esta categoria de análise, a maioria dos tutores pesquisados percebe sua interação (23 tutores) e prática tutorial (22 tutores) como adequadas ao atribuírem notas excelente e boa nas respostas à questão correspondente.

\section{Categoria 2: Formação inicial atende parcialmente às exigências para a prática tutorial}

Esta categoria foi construída a partir das questões que se referem à formação inicial e continuada dos tutores, que atende a um dos objetivos específicos da investigação. Foi possível constatar que a formação inicial não atende integralmente às exigências do MEC (BRASIL, 2016). Apesar de os tutores serem graduados e muitos possuírem pósgraduação, a maioria (14) não foi nem é professor presencial, o que a Portaria 183 (BRASIL, 2016) exige para a prática tutorial.

\section{Categoria 3: Formação continuada e capacitação estão adequadas}

Se a formação inicial não se enquadra totalmente às exigências da legislação da $\mathrm{EaD}$, nesta categoria, é possível dizer que a formação continuada e a capacitação dos tutores estão adequadas, pois a maioria (19) possui especialização. Portanto, apesar de não haver exigência de pós-graduação para o exercício da tutoria em Educação a Distância, o quadro de tutores da instituição pesquisada possui professores com formação continuada, sendo que alguns (4) possuem mestrado.

Pimenta e Anastasiou (2008) defendem a formação continuada dos professores do ensino superior, e os tutores, apesar da nomenclatura, são professores ao serem responsáveis pela mediação pedagógica na EaD. No Instituto Tecnológico de Monterrey, no México, por exemplo, os tutores são chamados de professores assistentes, conforme 
Fahara e Castro (2015).

\section{Categoria 4: Entende que a produção do material didático não deve ser atribuição do tutor, conforme Manual de Atribuições da UAB}

Esta categoria deixa claro que os tutores acreditam que possuem uma carga grande de atividades durante o processo de mediação pedagógica, concordando, portanto, com o Manual de Atribuições da UAB (BRASIL, 2009), que determina que o material pedagógico deve ser construído pelo professor formador. No entanto, é importante ressaltar que alguns tutores (4) discordam do Manual por acharem que o tutor deve participar do processo de elaboração das disciplinas, pois são eles que interagem com os estudantes, tiram suas dúvidas e são responsáveis pela avaliação.

\footnotetext{
Se não houver essa interação, o professor tutor ficará reproduzindo o que já está escrito nos materiais didáticos, estabelecendo-se aquele modelo antigo de educação a distância por correspondência, em que se recebia um material pronto e acabado, lia-se e respondia-se. O professor tutor não é um gravador que reproduz ao aluno os conceitos absorvidos do professor pesquisador. Ele é um professor: é de sua natureza a consciência de compreender para ensinar (BROD; RODRIGUES, 2016, p. 646).
}

Sendo assim, é necessário refletir sobre esta categoria, pois alguns tutores, que disseram concordar ou assinalaram a resposta não discordo nem concordo com o Manual de Atribuições da UAB, justificaram suas respostas admitindo a importância do tutor no processo de construção das disciplinas: "Acredito que o material deveria ser elaborado em conjunto professor formador e tutor, pois o tutor geralmente é mais próximo da realidade de ensino dos alunos" (TUTOR 2). Ou: "Concordância parcial, pois acredito que o tutor tem maior contato com os alunos, conhecendo melhor que 0 professor, quais as dificuldades de aprendizado dos alunos, portanto podendo propor materiais de estudo complementares" (TUTOR 5).

\section{Considerações finais}

A importância da interação e da mediação pedagógica no processo de ensino e aprendizagem da EaD é confirmada pelos tutores pesquisados, que consideram que realizam a interação com os estudantes e a mediação pedagógica de forma adequada. A disponibilidade constante dos tutores, via plataforma Moodle e outros meios de comunicação, até não oficiais do programa, como redes e aplicativos sociais, é um indício, para eles, dessa interação satisfatória.

No quesito formação pedagógica, constatou-se que a inicial não atende às exigências legais, já que os tutores devem ter experiência no magistério para atuarem na tutoria de 
EaD. Porém, a formação continuada, com a verticalização dos estudos, é adequada, visto que a maioria possui especialização, e alguns, mestrado.

Em relação à construção do material pedagógico, os tutores acreditam que o Manual de Atribuições da UAB está correto, ao determinar que essa função é do professor formador. A pesquisa revelou que os tutores consideram que possuem muitas tarefas e a construção do material pedagógico seria mais uma. No entanto, o questionário deixa a certeza de que esse assunto é polêmico e merece um maior aprofundamento, o que foi feito, na pesquisa mais ampla, com as entrevistas semiestruturadas e a observação num polo de EaD.

\section{Referências}

ABED - ASSOCIAÇÃO BRASILEIRA DE EDUCAÇÃO A DISTÂNCIA -. Censo EAD.BR - Relatório Analítico da Aprendizagem a Distância no Brasil 2016. Disponível em: http://abed.org.br/censoead2016/Censo_EAD_2016_portugues.pdf. Acesso em 10 maio 2018.

ARETIO. Pasado y presente de la acción tutorial en la Uned. In L. G. Aretio, A. O. Domingo et al. (Eds.), Perspectivas sobre la función tutorial en la UNED, p. 19-54. Madrid: UNED, 1999. Disponível em: http://migre.me/wKbOU. Acesso em 10 mai. 2018.

Educación a distancia y virtual: calidad, disrupción, aprendizajes adaptativo y móvil. RIED. Revista Iberoamericana de Educación a Distancia, v. 20, n. 2, p. 09-25. Madri, 2017. Disponível em: http://dx.doi.org/10.5944/ried.20.2.18737. Acesso em 09 maio 2018.

BRASIL. MINISTÉRIO DA EDUCAÇÃO. FNDE. Resolução CD/FNDE oㅜ 26, de 5 de junho de 2009: Anexo I - Manual de atribuições dos bolsistas da UAB. 2009. Disponível em: http://migre.me/wKbl7. Acesso em 09 maio 2018.

CAPES. Portaria no 183, de 21 de outubro de 2016. Regulamenta as diretrizes para concessão e pagamento de bolsas aos participantes da preparação e execução dos cursos e programas de formação superior, inicial e continuada no âmbito do Sistema Universidade Aberta do Brasil (UAB). Diário Oficial da União. Brasília, DF, 24 out. 2016. Disponível em: http://migre.me/wKbAG. Acesso em 09 maio 2018.

CONSELHO NACIONAL DE EDUCAÇÃO. CÂMARA DE EDUCAÇÃO SUPERIOR. Resolução oํ 01, de 11 de março de 2016. Estabelece Diretrizes e Normas 
Nacionais para a Oferta de Programas e Cursos de Educação Superior na Modalidade a Distância. Disponível em: http://migre.me/wKbBh. Acesso em 12 abr. 2017.

, Decreto 9.057, de 25 de maio de 2017. Regulamenta o art. 80 da Lei n. 9.394, de 20 de dezembro de 1996, que estabelece as diretrizes e bases da educação nacional. Disponível em: http://migre.me/wKbMf. Acesso em 11 maio 2018.

CHACÓN, Jorge W.B.; HERRERA, Juan Carlos B. El acompañamiento al aprendizaje en la formación con incorporación de Tic: una apuesta desde la sistematización de experiencias. Suplemento Signos EaD, IX Conferencia Internacional Guide, p. 01-15, 2016. Disponível em: http://p3.usal.edu.ar/index.php/supsignosead/article/view/3703. Acesso em 15 mai. 2017.

CHAQUIME, Luciane Penteado; MILL, Daniel. Dilemas da docência na educação a distância: um estudo sobre o desenvolvimento profissional na perspectiva dos tutores da Rede e-Tec Brasil. Revista Brasileira de Estudos Pedagógicos, v. 97, n. 245, 2016. Disponível em: http://migre.me/utFV2. Acesso em 10 abr. 2017.

DOS SANTOS JUNGES, Kelen; BEHRENS, Marilda Aparecida. Prática docente no Ensino Superior: a formação pedagógica como mobilizadora de mudança. Perspectiva, Florianópolis, v. 33, n. 1, p. 285-317, 2016. Disponível em: http://migre.me/wKbyx. Acesso em 15 mai. 2018.

FAHARA, M. F.; CASTRO, M.L. Teaching strategies to promote immediacy in online graduate courses. Open Praxis, v. 7, issue 4, p. 363-376, 2015. Disponível em: https://openpraxis.org/index.php/OpenPraxis/article/view/228. Acesso em 15 mai. 2018.

MILL, Daniel. Docência virtual: uma visão crítica. E-book. São Paulo: Papirus, 2012.

MOORE, M. G. Teoria da Distância Transacional. Revista Brasileira de Aprendizagem Aberta e a Distância, v. 1. São Paulo, 2002. Disponível em: http://migre.me/wKbpV. Acesso em 14 mai. 2018.

MOORE, M. G; KEARSLEY, G. Educação a distância: uma visão integrada. 3 $3^{\text {a }}$ reimpressão da 1. ed. São Paulo: Cengage Learning, 2010.

PIMENTA, Selma Garrido; ANASTASIOU, Léa das Graças Camargos. Docência no ensino superior. 3. ed. São Paulo: Cortez Editora, 2008. 
